\title{
Study on the Changing landscape of financial Services in Indian Banking System- Opportunities and Challenges
}

\author{
Pradeep M. D. ${ }^{1}$ \& Sonia Delrose Noronha ${ }^{2}$ \\ ${ }^{1}$ Research Scholar, School of Law, Alliance University, Bengaluru \& Assistant Professor, \\ College of Social Sciences \& Humanities, Srinivas University, Mangaluru, Karnataka, India \\ ${ }^{2}$ Research Scholar, Srinivas University, Mangaluru \& Assistant Professor, College of \\ Management \& Commerce, Srinivas University, Mangaluru, Karnataka, India \\ E-mail: mdpradeepnair767@gmail.com
}

Type of the Paper: Research Paper.

Type of Review: Peer Reviewed.

Indexed in: OpenAIRE.

DOI: http://doi.org/10.5281/zenodo.1147197.

Google Scholar Citation: IJMTS

\section{How to Cite this Paper:}

Pradeep M. D. \& Nornha Sonia D. N. (2018). Study on the Changing landscape of financial in Indian Banking System- Opportunities and Challenges. International Journal of Management, Technology, and Social Sciences (IJMTS), 3(1), 1-10.

DOI: http://doi.org/10.5281/zenodo.1147197.

International Journal of Management, Technology, and Social Sciences (IJMTS)

A Refereed International Journal of Srinivas University, India.

(C) With Authors.

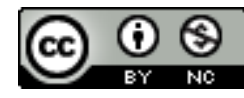

This work is licensed under a Creative Commons Attribution-Non Commercial 4.0 International License subject to proper citation to the publication source of the work.

Disclaimer: The scholarly papers as reviewed and published by the Srinivas Publications (S.P.), India are the views and opinions of their respective authors and are not the views or opinions of the SP. The SP disclaims of any harm or loss caused due to the published content to any party. 


\title{
Study on the Changing landscape of financial Services in Indian Banking System- Opportunities and Challenges
}

\author{
Pradeep M. D. ${ }^{1}$ \& Sonia Delrose Noronha ${ }^{2}$ \\ ${ }^{1}$ Research Scholar, School of Law, Alliance University, Bengaluru \& Assistant Professor, \\ College of Social Sciences \& Humanities, Srinivas University, Mangaluru, Karnataka, India \\ ${ }^{2}$ Research Scholar, Srinivas University, Mangaluru \& Assistant Professor, College of \\ Management \& Commerce, Srinivas University, Mangaluru, Karnataka, India \\ E-mail: mdpradeepnair767@gmail.com
}

\begin{abstract}
Financial institutions are the backbone of the Indian economy. Since economic liberalization after 1990, the Indian banking sector has witnessed growth along with remarkable improvement in its quality of assets and efficiency. Information Technology has become one's way of life in today's world that, it is difficult to imagine a world without IT. Technology which facilitates handling increased volumes at higher levels of efficiency. Hence, there is an imperative need for not mere technology up gradation but also integration of technology with the general way of functioning of banks. The Banking sector is no exception to this changing scenario which is sweeping across the world. Technology has given birth to a new era in banking. Indian banks are continuously encouraging the investment in information technology through ATMs, Netbanking, Mobile and Tele-banking, Automation of the banks, increasing use of plastic money, and the establishment of call centers. Nowadays banks are moving from disbursed operations to a centralized environment, powered by Information Technology. Banks are using new tools and techniques to reach better to its customers by offering tailor made products and Services. The changes in the banking landscape facilitated banks to compete in the new environment. Banks of the future will be a user friendly enterprise with technology aiming to achieve sustainable and valued business status. Information Technology has been imbibed in the banking operations with a vision to provide "Anytime Anywhere Banking” with customized services. In this paper we have discussed and analyzed the Changing landscape of financial Services in Indian Banking System in terms opportunities and challenges of technological developments, legal regulatory framework, and risk management.
\end{abstract}

Keywords: Economy, Information Technology, Banking, Business, Change, Customers, Banks.

\section{INTRODUCTION :}

Indian banking is at the threshold of a paradigm shift from the traditional branch banking to customized banking system. Technology aided financial services focus on customer centric commitments in order to meet their needs and expectations with customized services. Modern customers demand for banking services powered through Information Technology in the form of Net Banking and Mobile Banking due to the fact of having characteristics close to ideal banking system characteristics [1-5]. The tracking of banking transactions by visiting the branch is getting outdated with time. Traditional indicators of bank performance in the form of growth in deposits are taken over by the new parameters of Net Interest Margins, Non Performing Assets and Profitability. Technology facilitated to convert financial transactions, customer experience, marketing aspects into cashless and paperless. By 2020, it is estimated that average Indians belongs to younger generation with financial and social 
independence, who are tech savvy and well connected in social media. Banks are trying to tap this category of customers with its user friendly products and services tailored as per their needs. The Digital India Programme brought changes in the National e-Governance Plan by introducing Broadband highways, mobile connectivity, public internet access programme, e-Governance and e-Kranthi. Computerization improves the efficiency of banking transactions by achieving higher performance without corresponding increase in the employees which is adopted by public and private sector banks for better productivity [6].

\section{Incubation of IT into Banking Operations}

As a famous saying goes 'The future belongs to those who prepare for it today', financial business of tomorrow has to be planned today with Information Technology, which reconciled the working of banks and financial institutions throughout the world. It was recognized that, the success key for Indian Banking System is Information technology. Dr. C. Rangarajan Committee in 1984, recommended for the computerization and automation of branches, regional, zonal and head offices of banks and suggested to the bankers to receive the computerization process in the spirit of improving service to meet customer satisfaction [7]. The adoption of Information Technology in public sectors began an headway in improving the service utility in many sectors. The adoption of IT in banking brought several changes in banking with the passage of time it has become an inseparable segment of banking organization. It introduced new banking aspects such as ebanking, internet banking, online banking, mobile banking, Automated Teller Machines (ATMs), Universal Banking, Investment Banking, Core Banking etc. influencing banking operations with intensive phase [8].

\section{TECHNOLOGICAL DEVELOPMENTS IN BANKING SECTOR :}

\section{(a) Usage of Social Media Platforms}

Exchange of Information is made easy with the help of Internet which is a globally connected network. Usage of Internet for checking bank balance, mini statements, cheque books, upgradation of debit cards and purchase of virtual goods is taking dominance. Banks are now using social media platforms to reach its customers through launching multi social payment applications facilitating money transfer through social media channels. Unpredictable changes are brought in the society by using Information Technology as a medium of communication. Internet has redefined the methods of communication, work, education, entertainment, health, trade and commerce by eliminating the geographical distance between the banks and customers. It is inevitable for the banks to focus on the service quality and utility by meeting the changing customer needs for technology aided services like ATMs, etransfers, e-Commerce etc to survive and prosper in the present days [9-12].

\section{(b) Mobile based Banking}

Now more than $80 \%$ of the Indian Population possess mobile phones which brought a steady rise in the mobile payment volumes. The Study report of Accel Partners on e-commerce reported about an increase of $150 \%$ during 2016 in the rate of shopping through mobile phones from the rate of $800 \%$ prevailed in 2013.

\section{(c) Usage of Internet Services}

It is beyond our imagination to think to conduct banking operations anywhere in the country by using powerful yet simple medium of internet even from roadside kiosks. But which is made a reality to owe the credit of banking everywhere with the rampant use of Internet as a platform in banking. The advancement with electronic banking, electronic funds transfer and other similar products transfer of money is made possible in fraction of minutes which appeared impossible few years ago. With the entry of new players into the arena of fund transfer services created threats over the pride state of dominance enjoyed by banks in this regard. The World Wide Web (WWW) has become a convenient channel of universal communication.

\section{(d) Electronic Commerce}

Banks and Financial Institutions have hosted their official websites on the web to provide information about their profile, management details, various products, value additions to its services and rules and terms of services to enrich 
the interaction with clientele in a convenient and absolute way. Internet has stepped out to introduce electronic commerce to reach the business entities in exclusive way with static web pages allowing interactive two way system with the invention of the software technology. E-Commerce is a system, deals with buying, selling and distribution of goods and services directly to the customers with an aim to earn general revenue. E-Commerce helps to conduct traditional commerce in an innovative ways of transferring and processing information which is known to be the core of commercial activities.

\section{(e) Core Banking}

All the banks have implemented core banking systems and some are halfway through this process [13]. This system will link all the branches of the same bank and other banks and ATM Services to provide convenient banking service to the customers. It manages cash flows, reconciliation of all financial efforts and Management Information Systems (MIS) by using Internet and server technology. Customers can use this platform to submit Registration of Account Statements through e-mails on daily, weekly, fortnightly and monthly basis respectively, stopping payment of cheque, cheque book replenishment, demand draft or pay order, opening of Fixed Deposit/Recurring Deposit Accounts etc.

\section{(f) Electronic Banking}

With the introduction of E-Banking financial institutions have enriched the expectations upon the technology based services among the people. It is observed that in the era of liberalization, privatization, globalization and Information Technology, Indian Banking is under massive transformation in many segments by altering the face of banking by stepping towards e-banking from traditional banking. Most of the customers are satisfied with the utilities of the services rendered through e-channels but the lack of awareness to use these services effectively has become a major obstacle in this regard [14]. The registered user has to enter his corporate id, user id and password for accessing this facility and can view all his accounts online and can carry fund transfers on real time basis within the bank networks. The fund transfers are stored in the database of the bank and available to him to integrate with his Management Information System.

\section{(g) Electronic Security Measures}

The advancement in computing and telecommunication have revolutionaries the financial industry by introducing alternative delivery channels including ATMs, telebanking, remote access, internet banking services etc. but, trust upon the security aspects of these channels need to be ensured through installation of security systems to protect personal data and transactions with authentication and identify of user, confidentiality, integrity and non repudiation [15-18]. The software engineers introduced Site Security Firewalls, Filtering Routers, Secured Socket Layer, 128-bit encryption environment, Ver-sign Digital Certification etc. in this regard. Firewall is a system designed to provide security for corporate systems and public internet by prohibiting incoming network connections on selective or full basis allowing users to dial out but prohibiting them to dial in. A router to filter hackers of information on predetermined rules. Secured Socket Layer (SSL) protocol helps browsers and web servers with security services of encryption, digital certification and message integrity to prevent malicious or unauthenticated user from accessing the customer's account. These innovations cleared barriers in the facets of electronic banking to some extent rendering immense benefit to the customers with an accuracy of transactions. The concept of small office home office (SOHO) provides service to the customers round the clock anywhere to bank without visiting branches from his desktop. Full proof devices are introduced to ensure total security to prevent hacking of the websites. Additional features of digital signatures and biometric techniques are also introduced into banking systems. A confidential Safe Password key is provided to every customer, to which even the bank employees do not have access is provided to have absolute security to all. No Memory catch technology is installed on the navigators in the sites in order to protect the customers who have logged out by preventing another person to access back of the banking 
transactions by pressing 'Back' button on the navigator. 'Time Out' system is installed keeping the duration of 'five minutes' on the screen the lapse of specified time, makes the system to log out the viewer from the site automatically.

\section{(h) Software Development}

The IT experts have started developing customized software's adding social intelligence technology to banking operations. Banks started hoisting official websites on the Web to publish its virtual corporate image to the world. Software's replaced manual processing of data with inter branch reconciliation, processing monthly salary, posting and finalization of financial accounts, preparation of annual statements by consolidating transactions of several branches lead to higher productivity. This also facilitated in the sale of products to individual customers offered from insurance companies, stockbrokers, mutual fund experts and corporate entities.

\section{(i) Digital Signatures}

The electronic signature was introduced by using public- key cryptography as per the Information Technology Act. Cryptography is based on the use of algorithmic functions to generate two different mathematically related "keys". One key is used for creating a digital signature or transforming data into an unintelligible form, and other is used for verifying the digital signature of returning the message to its original form. Before the sender digitally signs an electronic communication, the sender must create a public private key pair. The 'Private key' is kept confidential and is used only by the signer to crate the digital signature. The 'Public key' is used by the relying party to verify the digital signature. A Third party, i.e., the certification Authority is entrusted to verify the key pair among the two parties. The Vasudevan Committee has recommended that the Reserve Bank of India may consider the Institute for Development of Research in Banking Technology (IDRBT), Hyderabad, as the Certification Agency for Security Management for the Financial Sector.

\section{(j) Adoption of Intranet}

It is a Wide Area Network (WAN) works like the internet with restricted to specific users or institutions by prohibiting the external access. The Head Office or Administrative Offices are thus linked with the systems of the branches through intranet. In this process, MIS returns for any branch can be directly compiled at the Administrative office. This facilitates to solve the problem of reconciliation of inter-branch accounts. It helps the big organizations employing thousands of persons and operating in a geographical outlay to develop an enormous internal routine and administrative systems and procedures. It allows single point computerization but, inter-linking the data of different geographical units is possible by linking the network of different branches/ geographical units by using the internet.

\section{(k) Corporate Internet Banking (CIB)}

E-Banking services are achieved through the channels of ATM's, Tele-banking, Mobile Banking, Internet Banking which have a wide scope for growth and challenge on the aspects of security by using internet [19]. CIB helps to access accounts of various branches of the banks and keep track on accounts maintained at different branches through a click of a mouse. This facility provides information about account, fund transfers, making business requests, database on individual account including the current balance, details of cash credit limits, drawing power etc. it allows the downloading of statements of accounts in the excel or text document files. The statements can also be integrated with customer's Enterprise Resource Planning System (ERPs) for auto authentication. The ERP can be used to transfer bulk fund between two linked accounts by specifying user cap and number of approvals required for the transfer. The fund transfer will not take place until the required number of signatories approves it. By taking Power of Attorney from the dealers, one can link dealer's account to their account and dealer with the customer to transfer fund online in order to save time and money involved with cheque collection process. EBanking and E-Financial Services are the branches of Electronic Commerce. It also opens up a new challenge to safeguard the interest of the service providers and service seekers with 
secrecy, security and integrity of stored and transmitted data by preventing unscrupulous hackers from interference and manipulation of valuable banking details.

\section{(l) Subsidiary Services}

(i) Micro ATMs: Banks started delivering banking services in the remote areas with Micro ATM's using devices working with mobile platforms and card reading facility aiding to transfer data using USSD Technology which does not require a smart phone or internet connection to access larger rural poor population. The banking correspondent uses this device to deposit or withdraw money for illiterate customers in the remote areas with scarce banking facilities as a step to integrate such region into core banking systems.

(ii) Payment of Bills: The problem of visiting different offices to settle his service bills of telephone, water, electricity, insurance, cable charges etc is crashed with the introduction of electronic bill transfer facility where one can pay his regular monthly bills by using e transfer technology from his desktop. Hassles related to missing the deadlines, loss of interest can be avoided by scheduling outstanding bills in advance in this system.

(iii) E-Shopping: The customer can do shopping from the different franchised shopping sites using authorized fund transfer channels without worrying about security aspects on such transactions.

(iv) Personal Investment: The banks provide personal investment in shares and other financial products. Electronic banking helps the customers to invest in mutual funds without undergoing the hassles of filling the application and other paper works even without providing signatures or proof of identity for investment. On reception of request for investment in a particular fund, the required fund will automatically debit and credit according to the debit or credit of his unit holdings.

(v) Trading in Shares: Banks provides 'cash trading' to deliver shares or money. Customer can use 'Margin Trading' as an inter settlement to the extent of four times of his available fund to buy or short sale of stocks in order to squaring off the position in the same settlement cycle.
'Spot Trading' of the shares through 'Cash on Spot' mode for immediate liquidity is allowed by crediting the money to the shareholder's bank account on the same evening without waiting till the exchange payout date. The money so deposited can be withdrawn through any ATMs. The customer can also trade directly at the recognized Stock Exchange of the country through his bank.

(vi) Credit Card Facility: Banks carries with credit card business or in collaboration with subsidiary companies having tie-ups it. Prior approval from the Research Bank of India is not required to undertake credit card business but, banks net worth has to be Rs. 100 crores. Bank carrying such business shall place a Comprehensive Review Report on half yearly basis covering data on credit card business specifying category, number of cards issued, outstanding or amounts written off, instances of frauds, profitability etc. Banks should take safeguards to conduct the credit card operations in a prudent and profitable manner with internal control systems to combat frauds. Banks shall actively participate in the committees and task forces constituted to form laws to prevent fraud by taking proactive fraud control and enforcement.

(vii) Smart Cards/Debit Cards: Prior approval of the Reserve Bank of India is not required in this regard but Bank shall take approval from their board of directors and furnish the details of smart/debit card issued along with a copy of the agenda note presented to the Board and resolution passed in this regard. Banks with a net worth of Rs. 100 crores and above can issue debit cards. It cannot issue smart or debit cards in a tie-up with other non-bank entities. Bank shall review debit card operations and put review notes before the board at the end of March and September every year and reported to the Chief General Manager, Department of Information Technology on a half-yearly basis.

\section{REGULATORY FRAMEWORK ON USING IT IN BANKING :}

The Government by keeping the objectives of building financial stability and customer protection, guided banks to devise financial 
inclusion plans into their business strategies by making them an integral part of their corporate business plans. Financial inclusion also includes access to wide range of financial services at reasonable cost. The Schemes like Pradhan Mantri Jan Dhan Yojana, Pradhan Mantri Suraksha Bima Yojana, Pradhan Mantri Jeevan Jyothi Bima Yojana and Atal Pension Yojana schemes are introduced in this regard.

\section{(a) Information Technology (IT) Act, 2000}

The communication system and digital technology have brought dramatic changes in the banking business. Many business transactions are carried out electronically with less regard to geographical distance of the trading partners. The law governing commercial transactions shall be consistence irrespective of the jurisdiction of the trading partners. The usage of Information Technology by the banks after taking into consideration of the short and long term planning to merge technology systems with business objectives [20]. Conscious efforts shall be taken to protect the organizational objectives by considering the holistic approach to national planning. Though electronic commerce eliminates paper based transactions which require legal authenticity. With the increasing usage of electronic means, it is required to demonstrate legal rights and obligations emerging out of it. The United Nations Commission on International Commerce in 1996 gave thrust to Government of India to frame IT policy. The parliament enacted Information Technology (IT) Act, 2000 to provide legal recognition to electronic Medias. Information is not denied from legal effect, validity or enforceability due to the electronic nature but based on the validity and authorization by using Electronic Data Interchange (EDI), Electronic Records and Electronic Signatures. The Act provides legal validity to Electronic Signatures and Electronic records by empowering Controller of Certifying Authorities to certify such signatures. The act identifies the following set of IT offenses listed in under the Chapter XI :

(i) Hacking: Destroying, deleting or altering any information from a computer resource or diminishing its value or utility by any means, with the intention to cause wrongful loss or damage to the public or any person.

(ii) Obscenity: Publishing or transmitting or causing to be published any obscene information or picture in electronic form.

(iii) Protected Systems: The government of India can declare any computer systems or computer network as protected system by providing access only to the authorized persons declaring contravention to be an offense.

(iv) Breach of confidentiality and privacy: Disclosure of any electronic record, book, register, correspondence, information, document or other material accessed/obtained without the consent of the person concerned.

(v) Publishing a digital signature with the knowledge that the certifying authority listed in the certificate has not issued it, or the subscriber listed in the certificate has not accepted it, or the certificate has been revoked or suspended.

(vi) Knowingly creating, publishing otherwise making available a digital signature certificate for any fraudulent or unlawful purpose.

\section{(b) Changes in Other Legislations}

Indian regulatory framework is constantly evolving with the stricter compliance norms and global standards on financial services. The regulators have become aggressive and strict in enforcement and making necessary changes to the regulations in order to maintain the International Technology and Service Standards. Certain changes are made in furtherance to the passing of IT Act, 2000 many other related legislations. The Indian Evidence Act, 1872 included word 'electronic record' along with the words record/document appearing under its various sections. Electronic records are also considered for evidence which is authenticated by digital signatures and certificates. The Indian Penal Code, 1860 under Section 446 specify about dealing with forgery of records including any list, data or record of any entries maintained in the electronic form authorized under the IT act. The Bankers Books Evidence Act, 1891 defined bankers books as ledgers, daybooks, cash books, account books and all other books used in the ordinary course of business of the bank, whether kept in written form or as printouts of data stored in a floppy disk, tape or 
stored in any other form of electromagnetic storage devices. The Reserve Bank of India Act, 1934 empowered the Central Board to make regulations for fund transfer through electronic means between the banks or banks and other financial institutions. It adopted IT to endorse the payment system's and modernization by developing Electronic Clearing Services (ECS), Electronic Funds Transfer (EFT), Indian Financial Network (INFINET), Real-Time Gross Settlement (RTGS) System, Centralized Funds Management System (CFMS), Negotiated Dealing System (NDS), Electronic Payment Systems with the 'Vision Document', Structured Financial Messaging System (SFMS) and India Card - a domestic card initiative (2011). The application of the act is excluded for the Negotiable Instruments, powers of Attorney, Trusts, Wills or other Testamentary Dispositions, Contracts for the sale of conveyance of immovable property or any interest in such property, and other forms of documents or transactions notified by the Central Government in the Official Gazette. The Black Money (Undisclosed Foreign Income and Assets) and Imposition of Tax Act, 2015 regulated accumulation of black money. The IT act, 2000 helps to develop e-governance and ecommerce by providing rules for validation and recognition of contracts formed through electronic means and permits the admissibility of computer evidence in the Court of Law. It also permits electronic filling of documents with Government Agencies [21].

\section{EVOLVING RISKS IN BANKING SERVICES :}

The technology aided financial services are exposed to varied risks crashing the technology, technological standards, and regulatory frameworks. The emerging banking scenario is exposed to Mail Spoofing, Web Spoofing, attaching the user computer, attacking Bank's server, media tapping and denying service etc. [22]. Phishing, identify thefts, card skimming, vishing, SMSishing, Viruses and Trojans, Spyware and Adware, website cloning and cyber stalking are the new threats in this regard. Banks offer online and mobile banking services facilitating payments through debit or credit cards or E Transactions which are highly vulnerable to sophisticated cyber attacks. PwC Global Economic Crime Survey 2014 reported that cyber crime is the one among the top economic crime as reported by organizations around the globe including India. With the extensive use of mobile technology through online platforms caused increased identity thefts. The Terror outlets are intensively using money laundering to fund terrorist activities which have compelled financial institutions to frame strict regulatory norms to conduct compliance checks to prevent such erroneous attempts on humanity. Global Financial Integrity Reports about 439.59 billion USD estimated at 28 lakh crores of Black money outflows to foreign countries between 2003 to 2012. The usage of Social Media platforms for financial transactions is prone to security breaches in the form of malware attacks [23-25].

\section{CONCLUSION :}

The Information Technology revolution has set the banking sector in motion towards national development. The rapid changes in the financial services lead to the increase of new players, product innovations by intensifying the competition [26]. It has become inevitable for the service providers to study the consumer behavior patterns to speed up their services to stand in the competition. Indian banking landscape is evolving with regional, state and national existence. The Banks should try to capture the Tech Savvy Gen-Y customers by designing customized products based on their needs. It also needs to deploy majority employees in sales and marketing aspects to cross sell varied services to its existing customers. The technology aided transactions by choosing right channel, IT investment in terms of Rate of Interest, e-governance, customer relationship management, security concerns, introduction of IT in rural areas cost much lesser than the traditional branch banking [27]. The demand for the skilled personnel's from other disciplines to work in banks also increases in the near future. Banks have to use the data analytics to gain feedback from the existing customers to 
improve their customer loyalty and business [28]. The best strategy to succeed in banking business is through initiating a partnership with multiple agencies to introduced varied services instead of working in many other segments. Banks should identify its core competencies and try to build it further. Bank should adopt the principle of 'One size fits all products' as a knowledge banker providing all financial services at a click [29]. Android platforms utilized with better, faster and convenient delivery channels will lead towards much profit. Indian banking environment is more compatible compared to the Standards of International Financial institutions by the positive impact of adoption of IT to the operational system of public, private and foreign sector banks in India. There is a need to set new standards for product and service delivery to satisfy the customer and ensure regulatory compliance to stay ahead in business. Banking in India aims to meet financial needs of the people by managing the existing risks of recovery by following the international regulations and utilization of easy delivery channels to compete in the global market [30]. Financial institutions should create awareness among the customers about chances of vulnerabilities and fraud existing in usage of latest technologies in financial operations to step ahead of the fraudsters [31].

\section{REFERENCES :}

[1] Aithal, P. S. (2016). Realization of Ideal Banking Concept using Ubiquitous Banking, International Journal of Scientific Research and Modern Education (IJSRME), 1(2), 119-135. DOI: http://dx.doi.org/10.5281/Z ENODO.164703.

[2] Aithal, P. S. (2016). Ideal Banking Concept and Characteristics. International Research Journal of Management, IT and Social Sciences (IRJMIS), 3(1)1, 46-55. DOI : http://dx.d oi.org/10.21744/irjmis.v3i11.311.

[3] Aithal, P. S. (2016). A Comparison of Ideal Banking Model with Mobile Banking System. International Journal of Current Research and Modern Education (IJCRME), 1(2), 206-224. DOI: http://dx.doi.org/10.5281/ZENODO.19870 $\underline{8}$.
[4] Krishna Prasad, K., Aithal, P. S. (2017). A Customized and Flexible Ideal Mobile Banking System using 5G Technology. International Journal of Management, Technology, and Social Sciences (IJMTS), 2(1), 25-37. DOI: http://dx. doi.org/10.5281/zenodo.820860.

[5] Krishna Prasad, K. and Aithal, P. S. (2017). A Study on Enhancing Mobile Banking Services using Location based Authentication. International Journal of Management, Technology, and Social Sciences (IJMTS), 1(1), 48-60. DOI: http://doi.org/10.5281/zenodo.583 $\underline{230}$.

[6] Parsons Darrell, Calvin C Gotlieb \& Michael Denny (1993). Productivity and Computer in Canadian Banking.The Journal of Productivity Analysis', Kluwer Academic Publishers, Boston, Netherlands, 4, 95-113.

[7] Indian Institute of Banking \& Finance, Mumbai (2008). 'Principles and Practice of Banking', Mac Millan Publishers India Limited, Chennai, $2^{\text {nd }}$ Ed., 265.

[8] Rajashekhara K. S., (2004) "Application of IT in Banking”, Yojana, A Development Monthly, July, 48, 22-25.

[9] Krishna Prasad, K. and Aithal, P. S. (2015). Massive Growth Of Banking Technology with the Aid of 5G Technologies. International Journal of Management, IT and Engineering (IJMIE), 5(7), 616-627. DOI : http://doi.org/1 $\underline{0.5281 / \text { zenodo.268879. }}$.

[10] Varambally K.V.M. \& Aithal P. S. (2009). Mobile Business Technology and Business Proliferation of Banks - A futuristic Approach Amity Business Review - an Indian Journal, 10(1), 9-25.

[11] Aithal, P. S., and Shubhrajyotsna Aithal, (2016). Opportunities \& Challenges for Green Technology in 21st Century. International Journal of Current Research and Modern Education (IJCRME), 1(1), 818-828, 2016. DOI : http://doi.org/10.5281/zenodo.62020.

[12] Ananthakrishnan G, (2004) Customer Service in Banks, Vinimaya, October-December, 25(3), 41. 
[13] Kamakodi N. \& Basheer Ahmed Khan M, (2008). Customer Expectations and Service Level in E-Banking Era: An Empirical Study', The ICFAI University Journal of Bank Management, November, VII (4), 50-70.

[14] Uppal R. K., (2008). 'Customer Perception of E-Banking Services of Indian Banks: SomeSurvey Evidence', The ICFAI University Journal of Bank Management, February, VII (1), 63-78.

[15] Raveendranath Hebbar, (2004). 'Building trust in E-Banking', Vinimaya, January- March, 24(4), 8.

[16] Aithal, P. S. (2015). Factors Affecting Banker's Perspective On Mobile Banking. International Journal of Management, IT and Engineering (IJMIE), 5(7), 28-38. DOI : http://doi.org/10.5281/zenodo.268816.

[17] Aithal, P. S., and K. V. M. Varambally, (2015). Customer Perspective on Online Mobile Banking in India - An Empirical Study. International Journal of Management, IT and Engineering (IJMIE), 5(7), 77-97. DOI : http://doi.org/10.5281/zenodo.268818.

[18] Aithal, P. S. (2016). A Review on various E-business and M-business models \& Research Opportunities, International Journal of Management, IT and Engineering (IJMIE), 6(1), 275-298. DOI : http://doi.org/10.5281/ zenodo.161146.

[19] Jadhav A. S. \& Mrs. R. A. Jadhav, (2004). 'Status of E-banking in India', National Annual Convention of CSI.

[20] Gulati V. P., Sivakumaran M. V. \& Manogna C, (2002). 'IT framework for Indian banking sector', ASCI Journal of Management, 31(1\&2), 67-77.

[21] Aithal, P. S., (2015). Recommendations on Policy \& Regulatory Guidelines For Mobile Banking in India. International Journal of Management, IT and Engineering (IJMIE), 5(7), 1-20. DOI : http://doi.org/10.5281/zen odo.2688 15.

[22] Radha V.\& Gulati V.P, (2004). 'Preventing Technology Based Bank Frauds’, The Journal of
Internet Banking and Commerce, Feburary, ISSN 1204-5357, 9 (1).

[23] Aithal, P. S. (2016). A Review on Advanced Security Solutions in Online Banking Models, International Journal of Scientific Research and Modern Education (IJSRME), 1(1), 421-429. DOI : http://doi.org/10.528 1/zenodo.160971.

[24] Krishna Prasad, K. \& Aithal P. S. (2016). Changing Perspectives of Mobile Information Communication Technologies towards Customized and Secured Services through 5G \& 6G. International Journal of Engineering Research and Modern Education (IJERME), 1(2), 210-224. DOI: http://dx.doi.org/10.5 281/ZENODO.198717.

[25] Aithal, P. S. (2015). Biometric Authenticated Security Solution to Online Financial Transactions. International Journal of Management, IT and Engineering (IJMIE), 5(7), 455-464. DOI : http://doi.org/10.5281/zenodo.2 $\underline{68875}$.

[26] Jain Abhay, \& Hundal B S, (2006). 'Barriers In Mobile Banking Adoption In India', ICFAI University Journal of Bank Management, August, V (3), 64-73.

[27] Uppal R.K., (2011). 'E Delivery Channels in Banks- A Fresh Outlook', Researchers World-Journal of Arts, Science \& Commerce, January, II (I), 178-188.

[28] Choudhari, S., Tripathy, A. (2003-04). Measuring Bank Performance: An Application of DEA, Prajnan, 32(4), 287-304.

[29] Soteriou, A. \& Zenios, S.A. (1999). 'Operations, Quality and Profitability in the Provision of Banking Services', Management Science, 45(9), 1221-38.

[30] Pradeep M.D. (2015). Impact of Information Technology in banking- Cyber Law and Cyber Security in India. International Journal of Management, IT \& Engineering, 5 (7), 411-428.

[31] ASSOCHAM India (2015). 'Current Fraud Trends in the Financial Sector', Price Waterhouse Coopers Pvt. Ltd, India, June, 23. 